\title{
Restoring Degraded Landscapes: Assessing the Utility of Biodiversity Offsets for the Business Sector in Africa
}

\author{
Claudious Chikozho and Derick De Jongh \\ Albert Luthuli Centre for Responsible Leadership \\ Faculty of Economic \& Management Sciences, University of Pretoria \\ Private Bag X20, Hatfield 0028, South Africa \\ Tel. +27 12420 6965; Email. c.chikozho@gmail.com
}

Paper Submitted to the International Journal of African Renaissance Studies

(IJARS)

February 2014

\begin{abstract}
Increasing pressure for the conversion of tropical and sub-tropical wetlands and forests to alternative land-uses raises the possibility that biodiversity offsets will increasingly take centre-stage in biodiversity conservation planning and ecosystem restoration discourses. This paper explores the major discourses on and utility of biodiversity offsets in the African context with a view to identifying and articulating some of the challenges and opportunities evident in attempts to operationalize the concept in practice. The paper establishes that as intuitively pleasing as they have become in recent years, with potentially large benefits expected to be derived from offset initiatives, several significant hurdles need to be overcome for them to become well-established practice in Africa. For instance, some observers have argued strongly that, in practice, land-use and wetland mitigation in most countries, has come nowhere near achieving the goal of 'no-net-loss'. There are also enduring questions surrounding the credibility of the formulae used to calculate net-losses and net-gains in biodiversity offset schemes. In the light of these and other outstanding questions, the paper concludes that biodiversity offsets may seem simple but are much more complex to design and implement to the extent that they become really convincing as a conservation tool for businesses in Africa.
\end{abstract}

Key words: Ecosystems; Conservation; Restoration; biodiversity-offsets; no-net-loss 


\section{Introduction}

In recent years, scholars and practitioners in the business and biodiversity sustainability sectors have been grappling with the possibilities of applying biodiversity offsets to address ecosystem degradation. Their interest in the concept is certainly not misplaced. Increasing pressure for the conversion of tropical landscapes for economic production raises the possibility that biodiversity offsets will increasingly take centre-stage in ecosystem restoration discourses. The Millennium Ecosystem Assessment (MEA) carried out between 2001 and 2005 is quite revealing in this regard. It concluded that about two thirds of all ecosystem services are in decline and this includes thousands of endangered species and substantial amounts and varieties of biodiversity (MEA, 2005). In the face of considerable decline of ecosystems in Africa and elsewhere, and continuing failure of mainstream conservation approaches to stop the degeneration, biodiversity offsets present an attractive alternative.

Observable trends in Africa and other parts of the world indicate that biodiversity offsetting is already gaining popularity in mainstream public policy and business sustainability discourses (Bishop et al., 2009). It is estimated that an unprecedented US\$22 trillion will be invested to support increased infrastructure development by 2030, mostly in developing countries (IFC, 2012; World Bank, 2007). These and other economic development activities are bound to increase the pressure on natural resources significantly as human populations grow. Suding (2011) points out that as environmental policy increasingly embraces restoration, the need to inform decision makers about effectiveness and uncertainty in restoration options has never been greater. Several governments in Africa have already been exploring policy options around biodiversity offsets and some private companies are now voluntarily undertaking biodiversity offsets for strategic business reasons. Many investors are now requiring clear biodiversity conservation plans as a pre-condition for accessing investment funds than in the past. Civil society groups are also now encouraging business developers whose activities directly impact the environment negatively to undertake biodiversity offsets as an ecosystem restoration alternative (see BBOP, 2012).

However, the utility of the concept faces a severe test in the African context where it is relatively new and the challenges and opportunities that arise in its practical application are not always readily evident. As more and more businesses on the continent and elsewhere begin to apply the concept in practice to improve their environmental risk management strategies, the need to interrogate this concept and clearly articulate some of the challenges and opportunities that inevitably arise from its application becomes crucial. More knowledge is required in this domain to enable the business sector to make better decisions regarding when, where and how to make use of biodiversity offsetting as an environmental management approach. In addition, a better understanding of its theoretical foundations and implications for practice is required if the concept is to be widely applicable and uptaken by various potential users. 


\section{Methodology}

Relying on a detailed review of the published literature and case studies of empirical experiences to-date, this paper assesses the utility of biodiversity offsets in the African context. The main intention is to identify and articulate some of the challenges and opportunities that emerge as businesses try to apply the concept in practice. Therefore, the paper explores ground common to ecology and corporate strategic planning. It addresses the question: to what extent and in what ways are biodiversity offsets useful as a tool for addressing ecosystem degradation and restoration? In our assessment, we endeavour to steer a reasonable path between the attractiveness of biodiversity offsets on the one hand and potential practical limitations to their application in Africa on the other. From the analysis, we are able to determine that in-depth analysis of the fundamental constraints and opportunities that offsetting offers to the field of ecosystem restoration in Africa remains one of the absolutely necessary ingredients. We outline the main assumptions behind the concept and directly address their implications for theory and practice in Africa. We also identify some of the world best-practices evident in this landscape.

\section{Conceptual foundations of biodiversity offsets}

The Business and Biodiversity Offsets Programme (BBOP) has taken the lead in promoting the application of biodiversity offsets throughout the world. As a result, most publications on biodiversity offsets borrow from the BBOP's definition, vis, once-off conservation projects tied to a given development, that specifically require 'measurable conservation gains, deliberately achieved to balance any significant biodiversity losses that cannot be countered by avoiding or minimizing impacts from the start, or restoring the damage done', and 'no net loss of biodiversity from the perspective of all relevant stakeholders' (BBOP, 2009). In simpler terms, offsets are specific projects designed to counterbalance, compensate, or make up for the disturbance of land, ecosystems and habitat, which occurs as many businesses engage in their productive activities. The idea is to counterbalance biodiversity loss through enhancing the state of biodiversity on-site or elsewhere (see Morris et al., 2006; Gibbons \& Lindenmayer, 2007; McKenney and Kiesecker, 2009; Madsen et al., 2011).

The ICMM (2013) classifies offsets into two main types, namely 'restoration offsets' and 'protection offsets'. Restoration offsets entail restoring, enhancing or establishing biodiversity, and are more common in the Organization for Economic Cooperation and Development (OECD) countries. Protection or averted loss offsets involve protecting biodiversity from further threats such as grazing, fire, overfishing and deforestation. In all cases, however, major focus is on compensating for an action harmful to ecosystems and tipping the balance towards the positive and, in the process, ensure that overall, there is 'no net-loss' to biodiversity (Bishop et al., 2009). Thus, in cases where key actors and public authorities determine that it is the most appropriate tool to be deployed, compensation for environmental damage may be undertaken away from the site of principal damage. This usually occurs when onsite compensation is deemed impractical or when greater conservation benefit 
would be secured by investing the same amount of resources elsewhere. Preferably a net-gain of biodiversity should be realized on the ground with respect to species composition, habitat structure, ecosystem function and people's use and cultural values associated with biodiversity (Landsberg et al. 2011; Doswald et al., 2012). At the same time, bio-diversity offsets done offsite do not necessarily replace the responsibility to minimise environmental damage onsite.

There are other scholars such as Rajvanshi et al. (2011) who argue that an effective offset project should deliver 'net benefits' for biodiversity beyond no-net-loss'. They may be 'in kind' or 'like for like' (loss and gain in the same attribute), 'out of kind' (loss of one attribute, gain in another 'substitute' attribute), or 'like for better' or 'trading up' (loss of one attribute, gain in another attribute of greater societal importance) (BBOP, 2012). For instance, if a private developer's activities take away wetlands in one neighbourhood, he or she may be required to provide an equivalent amount of wetlands, or ecosystem services in another area.

A message that cuts across most conceptualizations of the concept is that offsets should be treated as a last resort for developers seeking to compensate for unavoidable damage, after having applied the mitigation hierarchy (Kiesecker et al., 2010; Bull et al., 2013). This means that a developer should try to 'avoid, minimize and rehabilitate' any biodiversity impacts as much as possible, before considering and applying offsets to address residual impacts (BBOP, 2012). Therefore, quantifying residual ecological impacts arising from development, and creating equivalent biodiversity components elsewhere are core components of any offset project (BBOP, 2009; McKenney \& Kiesecker, 2010; Brownlie et al., 2012). The priority in the mitigation hierarchy is to avoid impacts, first by transparent exploration of all alternatives, then by avoidance through careful footprint design. The second priority is to minimise the impacts of a project on biodiversity; the third is restoration (see ICMM, 2013). A biodiversity offset is the final option in this 'mitigation hierarchy'; it is used only to tackle the remaining residual impact. In other words, an offset should only be considered after all other prevention and mitigation measures have already been factored into the proposal (ibid).

\section{Biodiversity offsets in Africa}

While substantive offset schemes have been implemented in several developed countries, case studies of vibrant offsetting schemes in Africa are not in abundance (Morris et al., 2006; BBOP, 2009). Madsen et al. (2011) state that in Africa, most countries are still exploring or developing biodiversity offsets policies and little progress has been made in terms of the implementation of these emerging policies. Consequently, any search for African case studies is most likely to lead one to some of the pilot projects being implemented by the BBOP in a few African countries such as South Africa, Uganda, Madagascar and Ghana. There are also a few voluntary offset initiatives undertaken by private businesses in South Africa, Uganda, Madagascar, Ghana, Guinea, and Mozambique with varying degrees of success (BBOP, 2012). So far most voluntary offsets in Africa have been undertaken by the mining and extractive industries, especially Rio Tinto, even though there are also a few examples from other sectors such as water. Most initiatives are now guided by 
the Standard on Biodiversity Offsets published by the BBOP in January 2012. It enables auditors and assessors to gauge the quality of mitigation measures, including biodiversity offsets, and helps offset developers to plan, design, implement and monitor offsets using best-practices (ICMM, 2013). The African offset cases will now be briefly considered in the next sub-sections.

\subsection{South Africa}

In South Africa, biodiversity offsets guidelines have been developed since 2007 for the Gauteng, Western Cape, and KwaZulu-Natal Provinces even though practical application has been lagging behind (DEA, 2011). At the national level, the DEA, in conjunction with South African National Biodiversity Institute (SANBI), has developed a national biodiversity offset framework enshrined in the 2013 Mining and Biodiversity Guideline (DEA/SANBI, 2013). Linked to the development of the national offset framework, SANBI's Freshwater and Grasslands programs are piloting the development of a wetland mitigation banking scheme as an offsets mechanism. The focus here is on the use of biodiversity planning tools to identify high-risk wetlands; methodologies for determining hectare equivalents and compensation ratios for wetland offsets; and on the development of guidelines for off-site offset arrangements. This will primarily serve the coal mining sector, but could also serve all sectors in terms of the precedent it will set.

Under the National Environmental Management Act of South Africa, three key elements in considering proposed biodiversity offsets are the significance of residual impacts, biodiversity values to be impacted and the ability of the applicant to implement mitigation measures (RSA, 2008). Significance ratings for residual impacts are given as low 'negligible impact', medium 'threshold of potential concern', high 'threshold of major potential concern' and very high 'the exclusionary threshold'. The exclusionary threshold relates to the fact that biodiversity offsets would not be considered when residual impacts would result in irreplaceable loss of biodiversity and ecological integrity (ibid). More specifically, it is clarified that these circumstances encompass very high residual impacts on:

(i) Habitats identified as Critical Biodiversity Areas in a published bioregional or fine-scale plan, or as a priority biodiversity area in other biodiversity plans, and/or as a core site in a biodiversity network;

(ii) Areas of irreplaceable biodiversity value identified by biodiversity specialists and supported by CapeNature, i.e. any habitat where its size, connectivity, structure, composition and condition would make it irreplaceable for ensuring persistence of an ecosystem or species;

(iii) Critically Endangered (irreplaceable loss) ecosystems identified in a biodiversity plan and ratified by a biodiversity specialist and/or CapeNature;

(iv) Critically Endangered species, assessed by a biodiversity specialist and/or CapeNature;

(v) 'Special habitats' recognized in a fine-scale biodiversity plan, by CapeNature or by a biodiversity specialist;

(vi) Fixed processes at provincial to local level, identified on the National Spatial Biodiversity Assessment or biodiversity or bioregional plans (i.e. with limited 
alternatives or substitutes and potentially important in enabling the persistence of biodiversity or delivery of ecosystem services of provincial importance);

(vii) Locally or provincially valued or important ecosystem services, with no local substitute (i.e. irreplaceable) or substitute only at high cost. Ultimately, however, only categories (ii) and (vi), above, are entirely not offsetable under this framework. Provision is given that all other categories may be offset in 'exceptional circumstances', with substantial multipliers, where the biodiversity feature to be impacted is highly unlikely ( $95 \%$ certainty) to be viable in the longterm (i.e. already 'doomed') or "proposed development would deliver substantial benefits to society and there are no reasonable and feasible alternatives that could be pursued to realize these benefits."

A particular point to note about the Western Cape guideline is the degree to which thresholds are not defined per se in the guideline, but in referenced policy and targets such as published bioregional or fine-scale plans, and the Provincial Spatial Development Framework - i.e. there is no goal of 'no-net-loss', but of reduction to a particular accepted conservation target level.

\subsection{Namibia}

BBOP (2009)'s report on Namibia reveals that the country has taken some steps to include the concepts of the mitigation hierarchy and "no-net-loss" in a Strategic Environmental Management Plan in response to a large increase in exploration and mining license applications. The country has been enacting a moratorium on issuing licenses since 2007 while a Strategic Environmental Assessment (SEA) was conducted for the Uranium Province (Erongo and Southern Kunene regions). In 2009, the SEA commenced and recommended biodiversity offsets "for the residual negative impacts in order to achieve a zero net loss to biodiversity and if possible make a net positive impact through other beneficial actions, e.g., supporting additional conservation activities." Following the SEA, a Strategic Environmental Management Plan (SEMP) was drafted to provide a framework for addressing the impacts of development. The SEMP included as one of its environmental quality objectives maintaining the ecological integrity of sites by employing a mitigation hierarchy, with biodiversity offsets as an option. A landscape-level spatial assessment to identify biodiversity conservation priorities and land-use opportunities and constraints within the Uranium Province was undertaken from 2011 through early 2012. The project included a focus on biodiversity offsets and aggregated offsets and was conducted under the auspices of the Ministry for Environment's Strengthening the Protected Areas Network programme.

\subsection{Guinea}

ICMM (2013) has documented the Simandou project in Guinea which is aligning offset site selection with national and international priorities. Rio Tinto Iron Ore is developing a large-scale resource in the Republic of Guinea in West Africa. The project involves mine, rail and port infrastructure, spanning $700 \mathrm{~km}$ from mine to port. At an early stage, the project recognized the importance of harmonizing its biodiversity approach with pre-existing national and international priorities. A dedicated working group has been established with representation from 
government, NGOs and Rio Tinto to ensure that the project's mitigation and offset plans are appropriately aligned with the Guinean Government's national biodiversity and protected areas strategy. This was recognized as critical because mining companies face significant risks in engaging in land use change at potential offset sites outside of their concessions, unless such interventions have been government approved.

\subsection{Madagascar}

Rio Tinto is investing in Tsitongambarika forest as a biodiversity offset designed specifically for biodiversity losses predicted for its QIT Madagascar Minerals (QMM) Ilmenite mining operations in Madagascar. The role of Tsitongambarika forest as a biodiversity offset is quantitatively mapped out in a recent IUCN-Rio Tinto report (Temple et al., 2012). In parallel, the mining company recognized that a range of ecosystem services would potentially also be provided by the biodiversity offset - for local communities, national government and indeed global stakeholders in the case of forest carbon emission abatement. An economic valuation of the ecosystem services of the entire forest (larger than the proposed offset site) was undertaken by IUCN which calculated that the ecosystem benefits include wildlife habitat (US\$2.9 million), hydrological regulation (US\$470,000) and carbon storage (US\$26.8 million). Potential ecotourism benefits (US\$2.5 million) were excluded from the analysis due to uncertainties in tourism revenues (Olsen et al., 2011). The study found out that there were significant net economic benefits associated with forest conservation (about US\$17.3 million net of all costs), mainly due to carbon storage values.

With reference to the offset projects done by Rio Tinto in Madagascar, Madsen et al. (2011) points out that standardization of ways to measure loss and gain of biodiversity is essential. For example, Rio Tinto's QMM mine is required to develop a set of currencies which are appropriate for each group of biodiversity values, be they threatened species, rare habitats or non-timber-forest products. A combination of the area in which a value is found and the quality of that area in supporting the value is considered a universally appropriate currency for both intrinsic and service values. Different measurement methods and metrics are used, as appropriate, for each type of biodiversity feature, to provide data for the "Area X Quality" currency (Hahn \& Richards, 2010).

\section{The business case for offsets}

Several scholars have been able to articulate the opportunities that biodiversity offsets create for businesses. Chief among these is that biodiversity offsets offer an approach that links conservation to industrial production processes, potentially providing improved ecological outcomes along with development. As Bull et al. (2013) point out, offsets can enable economic development to continue with no net loss and sometimes with a demonstrable net gain for biodiversity. Since most development activities inevitably have negative and unavoidable impacts on biodiversity, the impacts that cannot be remedied or mitigated on-site can be offset by enhancing the same or more threatened habitat at a separate nearby site. This creates the possibility to achieve a net gain in biodiversity, measured using selected ecological criteria (McKenney \& Kiesecker, 2010). In essence, the state of biodiversity 
should become better as a result of development than previously and the full variety is maintained or increased and some components are supposed to be left more secure than before (ibid).

Offsetting offers companies with high dependency and impacts on biodiversity, the opportunity to take proactive action by implementing voluntary offsets before the regulatory authorities open legal cases against them for infringements on the environment (ICMM, 2013). It also enables developers and investors to demonstrate that they are prepared to take full responsibility for their impacts on biodiversity. Through voluntary offsetting, companies demonstrate leadership, gain an ability to influence the regulatory process, and take advantage of new business development opportunities that may arise (Suding, 2011). Offsetting has potential as a more efficient, effective and elegant way of optimising land use and facilitating future development where it is optimal, while at the same time offering a means by which to halt further net loss of biodiversity and ecosystem services arising from development impacts (Olsen et al., 2011). It also offers the possibility that companies can begin to reverse some of the habitat and ecosystem losses (restoration and net gain) while stimulating jobs for small and medium sized enterprises in the rural economy (BBOP, 2012). It provides a transparent means by which to measure the 'residual or unavoidable impacts' of a development project and enables these to be compensated for by the creation or restoration of similar or 'better' nature elsewhere. It offers the potential not only for more, but for higher quality restoration of nature than has been the case in the past under business-asusual scenarios (Quétier \& Lavorel, 2011; Suding, 2011).

Other potential benefits to the business sector include a more streamlined and less uncertain permitting/licensing process; more sites released for acceptable developments; reduced long-term environmental liabilities; gain in net developable area; and corporate reputational gains (Hahn \& Richards, 2010). The ongoing offset initiatives by Rio Tinto in various countries in Africa demonstrate responsible leadership in this domain. While biodiversity offsetting may be achieved through non-market approaches, most theorists accept that a market approach, involving trading in offset 'credits', is most likely to take offsetting to another scale, streamline planning processes, reduce transaction costs and make the most meaningful contribution to national conservation priorities (Burgin, 2010; Doswald et al., 2012).

The ICMM (2013) outlines several further potential advantages evident in the deployment of biodiversity offsets. First, their quantitative nature makes them generally more transparent and possibly less open to criticism such as 'green-wash. Second, they may be the preferred form of risk management by regulators and lenders. Third, offsets have less risk of 'political capture' by interest groups by virtue of their more structured nature. For example, a politician may champion an investment in a particular national park, but a biodiversity offset requires broader stakeholder consultation. Fourth, biodiversity offsets allow companies to precisely link gains to losses to ensure that the most affected stakeholders are those who gain the most. It is therefore, not surprising that stakeholders in the conservation sector 
are increasingly interested in biodiversity offsets compared to other forms of compensation. This is because they are tangible, quantitative and enduring.

Research reports by the IUCN/ ICMM (2003) and the ICMM (2013) that seek to advance understanding regarding the business case for biodiversity offsets indicate that the private sector's involvement in voluntary biodiversity offsets is mainly motivated by, inter alia, their role in providing:

- The possibility of more in situ conservation activities than would ordinarily occur if developers were not encouraged to offset their impacts on biodiversity;

- A way to ensure better conservation outcomes by offsetting degradation of natural habitat of relatively low biodiversity value for conservation or restoration of high biodiversity value habitat (e.g. focusing on ecological corridors and priority sites) and by trading small, highly compromised sites for larger areas of habitat where conservation outcomes are more secure;

- The chance to internalise environmental 'externalities' and integrate biodiversity conservation into the investment plans of companies;

- Increased 'regulatory goodwill' which can lead to faster licensing and permitting;

- Better access to capital as financiers now want to see clear environmental management plans;

- Lower costs of compliance with regulations as companies address these in advance of the development activity; and

- Maximize strategic economic opportunities in emerging markets (for instance, establishing companies to implement offsets).

It is clear that if properly designed and implemented, biodiversity offsets offer a winwin situation for nature and companies. Clear biodiversity offset laws provide companies with legal certainty, efficiency and cost-savings in the planning process (Drechsler \& Wätzold, 2009). Doswald et al. (2012) states that mitigation of social and environmental impacts as part of any proposed development has increasingly become accepted good practice as companies strive to reduce exposure to reputational risk and develop a social and legal licence to operate. In the past, biodiversity offsetting did not play a crucial role for businesses due to the lack of clarity regarding the concept. However, offsets are now widely seen as a useful tool for managing the adverse impacts of development activities on biodiversity (Kate et al., 2004). Today, more and more companies are beginning to use biodiversity offsets as an alternative conservation approach. Beyond government regulation, numerous companies have already begun to set up biodiversity offsets voluntarily in places such as Qatar, Madagascar, and Ghana because they think it makes good business sense to do so (Bayon, 2011). However, like in the case of voluntary carbon markets, the number of investments in such offsets is still modest in Africa. In future, they are likely to become much more widely used as part of standard business practice. Currently BBOP is working with partners on projects in several countries across the globe. As these experiences mount up, and case studies become available on bestpracticea, it is likely that both the supply and demand for the offsets will grow (see BBOP, 2012). 


\section{Challenges for offsetting in Africa}

Despite the several observed and potential opportunities offered by biodiversity offsets, there is a vociferous group of experts and scholars who caution against too much optimism. Scholarship in this group argues that offsets are not necessarily the readily available panacea for the many biodiversity challenges associated with development projects (e.g. Kiss, 2002; Landell-Mills \& Porras, 2002; IUCN, 2004; Hahn \& Richards, 2010). Most of these scholars acknowledge that designing biodiversity offsets requires the resolution of a number of complex challenges against a background of incomplete information. We argue in this paper that these challenges have to be overcome first before the offset agenda can firmly take root in Africa. Some of the immediate concerns raised in most of the published literature relate to issues such as the reputation problems associated with poor outcomes and metrics, how best to design the offset initiative, its costs and timing, its application to different business sectors, and the eventual sequence of implementation (see Morris et al., 2006; Gibbons \& Lindenmayer, 2007; Bayon, 2011; Madsen et al., 2011; Suding, 2011).

Like any other project, an offset scheme will only be effective if it is adequately designed, implemented and enforced. Given the knowledge gaps that many African countries face in general, a key question then is whether or not the knowledge and skills required for the design and implementation of offset schemes are readily available on the continent. RioTinto has been leading offset efforts in Africa for several years now but recognises that they do not have the remit, skills or resources to assume sole responsibility for the long-term biodiversity protection and conservation of the areas where they work (see RioTinto, 2008). The issues and challenges facing the implementation of offsets in highly industrialized nations could potentially be magnified in Africa where conservation priorities often coexist with intense natural resource use, and there may also be differences in the language of legislation, policy and expertise (Kate et al., 2004).

Another enduring question that arises in most of the discourses on offsets is about how to accurately measure the ecological outcomes achieved when evaluating the performance of an offset program. Scholars such as McKenney and Kiesecker (2009) have categorically stated that measuring biodiversity and the success of conservation programmes is a challenging task. To this end, among the conservation and science communities, there is still no agreed framework. Most offset schemes often have the stated aim of producing a 'net gain' or 'no net loss' in environmental benefits but it can be challenging to determine in advance the actual impacts of a scheme and if, or when, it will achieve its objectives (Maron et al., 2010; Bull et al., 2013). In addition, political, economic, and ecological uncertainties further complicate efforts to gauge the likelihood of a scheme meeting its objectives. This is especially true given that the idea of offsetting is not always well-defined and can be implemented in various ways that may lead to different conservation outcomes (Diaz et al., 2007; Suding, 2011). In addition, while regulatory agencies in various countries often require that developers follow the mitigation hierarchy before considering an offset for the residual impacts, no quantitative guidelines exist to guide this decision-making process (Kiesecker et al., 2010). As a result, it is difficult for the business sector and 
other players to establish with certainty that no net-loss is actually happening on the ground (fallacy of no net loss).

Some of the assumptions on which the offset agenda is based are difficult to defend in reality. For example, the approach intrinsically implies that all habitats can be offset but it is now known that some habitats are irreplaceable and there are cases where a development project simply should not be permitted (IUCN / ICMM, 2003). Some components of biodiversity or ecosystems cannot reasonably be re-created, restored or rehabilitated (Pouzols et al., 2012). For example, old-growth forests, peat lands, slow-breeding or very demanding species, etc. In these cases, no residual losses should be accepted. This seems to be the case with the biodiversity in the Western Cape Province of South Africa (ibid). The ICMM (2013) concur with this view when they point out that there are definite limits to offsetting because some impacts are so large that they cannot be compensated for with a sufficient equivalent or in a socially acceptable way. This is especially critical when the project is likely to lead to irreplaceable loss of biodiversity, for example extinction of protected or classified species. This suggests that offsets are inappropriate for 'critical' or 'non-substitutable' biodiversity. This, however, is difficult to determine in Africa and guidance on the topic is still lacking. Suding (2011) argues that even when the area restored is larger than the area lost, compensation seldom succeeds in restoring ecosystem structure, composition, or function.

Studies done to determine the impact of road construction in Canada established that only a third of restoration goals were achieved in compensation projects to counteract the impacts (Tischew et al., 2010). In addition, restoration takes time to produce the same ecosystem functions as those provided by well-established habitats. The time-lag between habitat loss and restoration or recreation can substantially affect ecosystem function recovery (Diaz et al., 2007; Maron et al., 2010). In addition, how to precisely measure equivalency is one of the most debated of all technical offset issues. An offset would be regarded as equivalent if gains are scaled to balance losses in type, amount, quality, time and space. This will mean that gains are commensurate with losses.

Equivalency requires scientific and stakeholder consultation on many issues (Hahn \& Richards, 2010). It also requires establishing clear biodiversity baseline conditions. Under most offset instruments in Africa, these conditions are usually less clear (Quetier \& Lavorel, 2011; ICMM, 2013). Burgin (2010) argues that it is difficult to argue ecological equivalence between biodiversity components that differ in type, location, time, or ecological context. When the offsets are required to protect particular species or habitats, the task is easier. Nevertheless, no two areas are the same and some measure needs to be used to determine the equivalence of offsets (Doswald et al., 2012). For example, it can be demonstrated that a manmade wetland is demonstrably not equivalent to a naturally established wetland (Burgin, 2010). Therefore, an enduring question regarding the utility of offsets centres around when and where they can be used as an appropriate tool. In addition, if offset use continues to increase, how do we ascertain that impacts to biodiversity are actually being offset? In Africa where offset experiences are still few, and its 
methodologies are still under development, these are very critical questions. From a theoretical stand-point, rigorous post-offset implementation evaluation is likely to be the only credible way with which to ascertain whether or not no net loss and net gains are attained in the medium to long-term (ibid). Equally important, a track record of successful implementation in Africa is necessary to demonstrate that offsets actually work in practice.

Quétier and Lavorel (2011) identify several key points that require particular attention and advance clarity in order for offsets to be more meaningful. These include the definition of detailed target components of biodiversity and ecosystems (animal and plant populations, particular assemblages of species, community types, ecosystem properties, ecosystem services, etc.); Secondly, the development or selection of appropriate indicators (including landscape-level processes) and scoring procedures; the identification of appropriate baselines for calculating losses and gains; time-related issues (e.g. delays between losses and gains); and uncertainties in both assessment and offset outcomes. Maron et al. (2012) concur by questioning the extent to which biodiversity offset policies make restoration ecology realistic and feasible, given the state and complexity of the science. For example, impacts on wetlands and ancient woodlands are difficult to restore in terms of the time and technical skills required, as these habitats have evolved over many centuries. In addition, some species take a long time to recover and therefore, offsetting may not be achieved within reasonable human timescales.

Doswald et al. (2012) go a step further to point out that one of the most frequently cited risks of biodiversity offsets concerns their ethos: it is feared that offsets can in fact be 'a licence to trash' (develop environmentally unsustainable projects). This could lead to reputational risks for businesses and financial institutions. It also does raise important issues concerning the thresholds of each step in the mitigation hierarchy. Any contentious issue arising from undertaking a biodiversity offset, could lead to criticism and hence negate the business benefits (ibid). Thus, the main controversy surrounding offsetting seems to be related to the need to accept ecological losses in return for uncertain gains (Burgin, 2010). A reasonable fear becomes that biodiversity offsets will offer perverse incentives to companies and other actors by lowering the acceptance threshold of conservation outcomes. The cumulative effect of all these risks raises the need for credible and transparent standards, methodologies and guidelines for biodiversity offsets, if the approach is to be adopted more widely in Africa.

\section{Conclusion}

Most of the literature examined in this paper shows that biodiversity offsets have been receiving increasing attention in recent years and offer a new approach to ecosystem restoration that can reduce the impacts of business production processes on biodiversity. By tracing the basic tenets and principles behind biodiversity offsets, this paper has demonstrated the added-value and opportunities that the approach offers to businesses interested in pursuing a robust restoration agenda. Application of the mitigation hierarchy in conjunction with a well-developed offset program enhances the chances of more meaningful ecosystem restoration, with the 
possibility that some net-gains will be realized. Designing offsets with the clear intention to go beyond no net loss is also crucial in advancing the agenda for effective restoration. There are some evident challenges in applying and implementing biodiversity offsets in Africa and elsewhere. These include basic issues such as when, where and how this is most appropriately done, how best to ascertain that the intended ecosystem restoration outcomes will actually be achieved, and indeed what metrics to use to measure baseline and post-implementation biodiversity conditions in both terrestrial and aquatic-based projects emerges as a critical dimension of the concept.

Although investigation into how best to manage uncertainty in offsets is obviously a continuing effort in various countries, more research is still required on the development of a comprehensive framework for treating these uncertainties in Africa where the practice is still relatively new. A simple conceptual framework that integrates consideration of various key components of offsetting could facilitate a common approach to managing the challenges identified, and allow out-scaling of offset practices across the continent. Experiences from companies such as Rio Tinto that have taken the lead in implementing voluntary offsets should be documented and widely disseminated to inform future efforts. The paper has also demonstrated that despite the attractiveness of the approach, key players should be cautious and understand that biodiversity offsetting is not 'a license to trash'. Companies have to first follow the mitigation hierarchy, apply biodiversity offsetting to sites appropriate for such development and even then, only as a last resort.

Potential impacts on protected species and highly protected areas have to inform the decision to implement a project or not. In some cases, certain projects will simply have to be denied the license to take off by the regulatory authorities. The knowledge-base for understanding key considerations in biodiversity offsetting has to be broadened and deepened to resolve all the outstanding uncertainties and technical gaps currently besetting the landscape. However, restoration will always be a gamble up to a certain point. While restoration through offsetting is possible and may actually lead to net positive gains in the ecosystem, it may also not succeed as well as planned. This is a reality that businesses pursuing the offsetting agenda have to live with. Nevertheless, despite the existence of uncertainties and challenges in the biodiversity offsets landscape, the approach is officially gaining ground in many countries. Therefore, the question is no longer if biodiversity offsets will be a key aspect of the business and ecosystem restoration landscape in Africa in the near future, but exactly when, where, and how to apply them. Although insufficient information and tools exist to ensure success of biodiversity offsets in Africa, it is critical for restoration sciences to inform their out-scaling across the continent.

\section{References}

Bayon, R. 2008. "Banking on Biodiversity". In: World Watch Institute (2008) State of the World 2008 - Innovations for a Sustainable Economy. World Watch Institute, Copenhagen 
Bishop, J., Kapila, S., Hicks, F., Mitchell, P., Vorhies, F. 2008. Building Biodiversity Business. IUCN, Gland

Bishop, J., Kapila, S., Hicks, F., Mitchell, P., Vorhies, F. 2009. New Business Models for Biodiversity Conservation. Journal of Sustainable Forestry, 2009, Vol. 28, pp285-303

Business and Biodiversity Offsets Programme (BBOP). 2012. Biodiversity Offset Design Handbook-Updated. BBOP, Washington, D.C.

Business and Biodiversity Offsets Programme (BBOP). 2009. The Relationship between Biodiversity Offsets and Impact Assessment: A BBOP Resource Paper. BBOP, Washington, D.C.

Brownlie, S., King, N., \& Treweek, J. 2012. Biodiversity Tradeoffs \& Offsets in Impact Assessment \& Decision Making: Can we Stop the Loss? Impact Assessment and Project Appraisal Vol. 31, No. 1, March 2013, pp24-33

Bull, J. W., Suttle, K. B., Gordon, A., Singh, N. J. \& Milner-Gulland, E. J. 2013. Biodiversity Offsets in Theory \& Practice. Fauna \& Flora International, Oryx, pp1-12

Burgin, S. 2010. 'Mitigation Banks' for Wetland Conservation: A Major Success or an Unmitigated Disaster? Wetlands Ecol Manage (2010) 18, pp49-55

Department of Environmental Affairs \& Development Planning (DEA). 2011. Information Document on Biodiversity Offsets. EIA Guideline and Information Document Series. Western Cape Department of Environmental Affairs \& Development Planning (DEA \& DP), Cape Town, South Africa. Available at:

http://www.iaia.co.za/File_Uploads/File/DEADP_EIA_Info_Doc_on_Biodiversity_Offsets_Oct2011.pdf

Department of Environmental Affairs \& Development Planning/ SANBI. 2013. Mining and Biodiversity Guideline: Mainstreaming Biodiversity into the Mining Sector. DEA, Pretoria

Diaz, S., Lavorel, S., de Bello, F., Qu'etier, F., Grigulis, K. 2007. Incorporating Plant Functional Diversity Effects in Ecosystem Service Assessments. Proc. Natl. Acad. Sci. USA 104, pp20684-20689

Doswald, N., Barcellos H. M., Jones, M., Pilla, E., and Mulder, I. 2012. Biodiversity Offsets: Voluntary and Compliance Regimes - A Review of Existing Schemes, Initiatives and Guidance for Financial Institutions. UNEP-WCMC, Cambridge

Drechsler, M. \& Wätzold, F. 2009. Applying Tradable Permits to Biodiversity Conservation: Effects of Space-dependent Conservation Benefits and Cost Heterogeneity on Habitat Allocation. Ecological Economics, 68, pp1083-1092

Gardner, T. \& von Hase, A. 2012. Key ingredients for biodiversity offsets to achieve No Net Loss. Unpublished report to the New Zealand Department of Conservation. Available from: http://www.doc.govt.nz/upload/documents/conservation/key-ingredients-for-biodiversityoffsets.pdf

Gibbons P, Lindenmayer, D. B. 2007. Offsets for Land Clearing: No Net Loss or the Tail Wagging the Dog? Ecol. Mgmt Restor. 8, pp26-31. 
Hahn, R. \& Richards, K. 2010. Environmental Offset Programs: Survey and Synthesis. Sustainable Consumption Institute, Manchester.

International Council on Mining and Metals (ICMM) 2013. Independent Report on Biodiversity Offsets. Biodiversity Consultancy. Available at: www.icmm.com/biodiversityoffsets

International Finance Corporation (IFC). 2012. Performance Standard 6: Biodiversity Conservation \& Sustainable Management of Living Natural Resources. IFC, Washington, DC

IUCN / ICMM. 2003. Mining \& Biodiversity: Towards Best Practice. Summary and Discussion of the Results of the IUCN-ICMM Workshop on Mining, Protected Areas and Biodiversity Conservation: Searching and Pursuing Best Practice and Reporting in the Mining Industry. 7 9 July, 2003. Gland, Switzerland

Kate, K., Bishop, J. \& Bayon, R. 2004. Biodiversity Offsets: Views, Experience, and the Business Case. IUCN, London

Kiss, A. 2002. Making Biodiversity Conservation A Land Use Priority. Columbia University Press. Available at: http://epp.gsu.edu/pferraro/special/AgiBookChapter2002.pdf

Kiesecker, J.M., Copeland, H., Pocewicz, A. \& McKenney, B. 2010. Development by Design: Blending Landscape-level Planning with the Mitigation Hierarchy. Frontiers in Ecology and the Environment, Vol. 8, pp261-266

Landell-Mills, N. and I.T. Porras. 2002. Silver Bullet or Fools' Gold? A Global Review of Markets for Forest Environmental Services and their Impact on the Poor. IIED, London

Landsberg F, Ozment S, Stickler M, Henninger N, Treweek J, Venn O, Mock G. 2011. Ecosystem Services Review for Impact Assessment: Introduction \& Guide to Scoping. WRI Working Paper. World Resources Institute, Washington D.C.

Madsen, B., Nathaniel, C., Daniel, K. \& Genevieve, B. 2011. Update: State of Biodiversity Markets - Offset and Compensation Programs Worldwide. Forest Trends 2011, Washington, DC

Millennium Ecosystem Assessment (MA). 2005. Ecosystems and Human Well-being: Opportunities and Challenges for Business and Industry. World Resources Institute, Washington, DC.

Maron, M., Dunn, P.K., McAlpine, C.A., Apan, A. 2010. Can Offsets Really Compensate for Habitat Removal? The Case of the Endangered Red-Tailed Black-Cockatoo. Journal of Applied Ecology, Vol. 47, pp348-355

McKenney, B.A., Kiesecker, J. M. 2010. Policy Development for Biodiversity Offsets: A Review of Offset Frameworks. Environmental Management 45, pp165-176

Morris, R. K. A., Alonso, I., Jefferson, R. G. \& Kirby, K. J. 2006. The Creation of Compensatory Habitat-Can it Secure Sustainable Development? Journal for Nature Conservation, 14, pp106-116. 
Olsen, N., Bishop, J. \& Anstee, S. 2011. Exploring Ecosystem Valuation to Move Towards Net Positive Impact on Biodiversity in the Mining Sector. IUCN, Gland. Available at:

http://data.iucn.org/dbtw-wpd/edocs/2011-062.pdf

Pouzols, F. M., Burgman, M. A., \& Moilanen, A. (2012) Methods for Allocation of Habitat Management, Maintenance, Restoration and Offsetting, When Conservation Actions Have Uncertain Consequences. Biological Conservation, 153, pp41-50

Quétier, F. \& Lavorel, S. 2011. Assessing Ecological Equivalence in Biodiversity Offset Schemes: Key Issues and Solutions. Biological Conservation, 2011

Rajvanshi A, Brownlie S, Slootweg R, Arora R. 2011. Maximizing Benefits for Biodiversity: the Potential of Enhancement Strategies in Impact Assessment. Impact Assess Project Appraisal. 29 (3), pp181-193.

Rio Tinto. 2008. Rio Tinto and Biodiversity - Achieving Results on the Ground. Rio Tinto plc, London

Suding, K. N. 2011. Toward an Era of Restoration in Ecology: Successes, Failures, and Opportunities Ahead. Annual Review of Ecology Evolution \& Systematics, Vol. 42, 2011, pp465-87.

Temple, H. J., Anstee, S., Ekstrom, J., Pilgrim, J. D., Rabenantoandro, J., Ramanamanjato, J. B., Randriatafika, F. \& Vincelette, M. 2012. Forecasting the Path Towards a Net Positive Impact on Biodiversity for Rio Tinto QMM. IUCN, Gland, Switzerland.

Tischew, S., Baasch, A., Conrad, M. K., Kirmer, A. 2010. Evaluating Restoration Success of Frequently Implemented Compensation Measures: Results \& Demands for Control Procedures. Restoration Ecology 18, pp467-480

World Bank. 2007. Global Economic Prospects 2007: Managing the Next Wave of Globalization. World Bank, Washington, DC 